\title{
LA PRESENCIA DE LA VIOLENCIA EN LAS SERIES DIRIGIDAS A LOS NIÑOS/AS DE 5 Y 6 AÑOS. UNA PERSPECTIVA SEMIÓTICO-CULTURAL
}

\author{
Xana Morales Caruncho, Pedro D. Chacón Gordillo \\ y Pilar M. Soto Solier
}

\section{RESUMEN}

Partiendo de la premisa de que los niños/as de Educación Infantil son consumidores habituales de series con un alto contenido violento — conclusión que se extrae de un estudio previo al que aquí se presenta-, esta investigación se centra en analizar tanto los tipos de violencia que aparecen en estos productos audiovisuales como la caracterización que se hace de sus personajes protagonistas. A partir de aquí se trata de determinar la influencia que tienen estos productos en los niños/as de Educación Infantil recopilando una serie de dibujos realizados por diferentes grupos de niños/as de entre 5 y 6 años, unos dibujos que se enriquecerán mediante entrevistas a los propios niños/as para recabar su opinión. Los resultados tratarán de demostrar la sobrexposición de productos audiovisuales de tipo violento a la que los niños/as se ven sometidos y la repercusión que estas imágenes ejercen sobre la educación en edades tempranas.

Palabras clave: violencia, infancia, series de animación, cultura visual, semiótica cultural.

\section{TITLE: PRESENCE OF VIOLENCE IN TV SERIES AIMED TO 5 AND 6 YEAR OLD CHILDREN. A SEMIOTIC-CULTURAL PERSPECTIVE}

\section{ABSTRACT}

This research is based on a case study from which it has been concluded that Primary School children are regular consumers of series containing high levels of violent content. On this premise, this study focuses on analyzing both the types of violence appearing in these audiovisual products and the resulting portrayal of those in the leading roles. Based on this, it is a question of determining the influence these products have on Primary School children by compiling a series of drawings done by different groups of children aged between 5 and 6 . These drawings will be enriched through interviews with the children to obtain their opinion. The intention is for the results to demonstrate the overexposure of audiovisual products of a violent nature, to which children are subjected and the repercussions these images have on education at an early age.

Keywords: violence, childhood, cartoons, visual culture, cultural semiotics.

Correspondencia con los autores: Xana Morales Caruncho. < contacto@xanamorales.com>.Pedro David Chacón Gordillo. <pchacon@ugr.es>. Universidad de Granada. Pilar M. Soto Solier. <pm.sotosolier@um.es> Universidad de Murcia. Original recibido: 22-04-13. Original aceptado: 18-10-13 


\section{Introducción}

Hoy en día, la cultura visual infantil está conformada por muchos elementos, entre los cuales los productos audiovisuales televisivos dirigidos a los más pequeños tienen un papel esencial. Con respecto a esto, muchos observadores (Buckingham, 2005; Giroux, 1997; Leiva y González, 2000; Lipsky y Abrams, 1994; Steinberg y Kincheloe, 2000; etc.) han apreciado el hecho de que el bombardeo de imágenes propio de nuestra época tiene un impacto directo en el debilitamiento del concepto tradicional de infancia. Podría decirse que actualmente los padres no controlan del todo las experiencias culturales de unos hijos/as que están diariamente expuestos a una gran cantidad de imágenes cargadas de mensajes para consumir o para comportarse de una determinada manera, mensajes que moldean su comportamiento y los dirigen hacia una determinada forma de actuar, mensajes, en definitiva, que los construyen como personas y que les ofrecen una determinada visión del mundo. Tanto es así que podríamos considerar que los tutores o progenitores han perdido, en cierto modo, parte del papel que antes desempeñaban como desarrolladores de valores para los niños/as. De hecho, mientras en los años veinte del pasado siglo los más pequeños vivían pocas experiencias que no estuvieran observadas y controladas por los padres, hoy por hoy, el mundo de las imágenes referido a programas de televisión, películas de animación, televisión, DVD, Internet, videojuegos es un dominio privado que los niños/as no comparten con los adultos (Buckingham, 2005). Estos últimos han perdido la autoridad que los caracterizaba antaño, cuando eran conocedores de cosas que los niños/as ignoraban, pues actualmente son los propios niños/as quienes ven el mundo por sí mismos bajo la mediación de aquellos que crean las imágenes para el consumo infantil. Ante tal situación parece imprescindible el desarrollo de una educación que incida en este nuevo escenario, enseñando a los niños/as a dar sentido a las imágenes que les rodean, y teniendo en cuenta la superabundancia a la que quedan expuestos. La escuela debe, por lo tanto, convertirse en un espacio donde se construyan significados y expresiones y donde se aliente la comprensión e interpretación de la cultura visual infantil (Steinberg y Kincheloe, 2000).

Para ello, esta investigación, enmarcada dentro del ámbito de los estudios sobre cultura visual nace con la intención de analizar un elemento concreto del entorno visual y cultural de los más pequeños: Las series de animación infantil. Con esta intención se pone en marcha un trabajo empírico dividido en tres fases: 
- Un estudio piloto que toma la forma de un estudio de caso llevado a cabo en tres aulas de Educación Infantil de la ciudad de Granada y que pretende llegar a conocer cuáles son las series de animación infantil más consumidas en la actualidad por los niños/as de entre 5 y 6 años. De él se extrae la conclusión de que los niños/as de Educación Infantil son grandes consumidores de series con un alto contenido violento.

- Una primera etapa analítica, en la que se elabora un registro que permite contextualizar en el tiempo los símbolos y significados culturales presentes en las series audiovisuales más populares y con mayor carga violenta de las últimas décadas.

- Una segunda etapa empírica, en la que se trata de ir un paso más allá proponiendo a un grupo de niños/as de Educación Infantil que elaboren un dibujo sobre una serie de animación que vean habitualmente en televisión para comprobar si los significados que los niños/as otorgan a los contenidos de estas series son los mismos observados en la contextualización realizada de forma previa.

\section{Estudio piloto sobre las series de animación infantil más consumidas en la actualidad por los niños/as de entre 5 y 6 años}

Cuando en un primer momento se decide centrar esta investigación en el análisis general de las series de animación dirigidas a los niños/as más pequeños parece evidente que el primer paso es realizar un registro de aquellas series más consumidas por éstos. Para ello se pone en marcha un pequeño estudio de caso consistente en tres sondeos llevados a cabo en tres aulas de Educación Infantil de diferentes centros educativos públicos de la ciudad de Granada: La Escuela Infantil Pública de Jun y los Colegios Públicos Al-Zawiya de la Zubia y Luis Rosales. Estos centros son seleccionados con la voluntad de constituir la muestra con participantes de todos los estratos socioeconómicos, pues mientras el Colegio Público Luis Rosales se encuentra ubicado en pleno centro de la ciudad y cuenta con alumnos/as provenientes de familias de clase media y media-alta, los otros dos centros están ubicados en zonas periféricas, por lo que el nivel socioeconómico del alumnado es más variado. Finalmente, la muestra queda formada por 48 alumnos/as entre los cuales la media de edad se fija en los 5,5 años. 


\begin{tabular}{lccc}
\hline Escuela & $\mathbf{N}^{\circ}$ total de niños/as & $\mathbf{N}^{\circ}$ de niños & $\mathbf{N}^{\circ}$ de niñas \\
\hline Escuela Infantil Pública de Jun & 19 & 10 & 9 \\
\hline $\begin{array}{l}\text { Colegio Público } \\
\text { Al-Zawiya de la Zubia }\end{array}$ & 13 & 5 & 8 \\
\hline Colegio Público Luis Rosales & 16 & 10 & 6 \\
\hline$N^{\circ}$ total de participantes & 48 & 25 & 23 \\
\hline
\end{tabular}

Tabla I. Cuadro de población investigada durante el estudio piloto.

El sondeo que se lleva a cabo en cada una de estas tres aulas consiste en la realización de una entrevista en la que se pregunta a los niños/as cuáles son las series que más consumen a través del medio televisivo. Una vez obtenidas y registradas las respuestas se procede a la elaboración de un listado de todas las series de animación nombradas en el que se refleja en forma de porcentaje la frecuencia con la que cada una de las series es mencionada por los niños/as participantes en los sondeos. La Tabla 2 refleja las ocho series más populares entre los niños/as investigados, así como su porcentaje de visualización.

\begin{tabular}{|c|c|c|c|}
\hline \multirow[t]{2}{*}{$\begin{array}{l}\text { Serie } \\
\text { de animación infantil }\end{array}$} & \multicolumn{2}{|c|}{$\begin{array}{l}\text { No total de niños/as que ven } \\
\text { la serie en los tres centros } \\
\text { investigados }\end{array}$} & \multirow{2}{*}{$\begin{array}{l}\text { \% total de niños/as } \\
\text { que ven la serie en } \\
\text { los tres centros } \\
\text { investigados }\end{array}$} \\
\hline & Niños & Niñas & \\
\hline «Los Simpson», 1991 & 24 & 18 & $87,5 \%$ \\
\hline «Bob Esponja», 1999 & 17 & 14 & $85,41 \%$ \\
\hline «Los Gormiti», 2009 & 25 & 6 & $64,58 \%$ \\
\hline «Doraemon», 1997 & 14 & 10 & $50 \%$ \\
\hline «Shin Chan», 2000 & 13 & 11 & $50 \%$ \\
\hline «Bola de dragón», |99| & 10 & 2 & $26,66 \%$ \\
\hline «Pokemon», 1999 & 6 & 4 & $20,83 \%$ \\
\hline «Padre de familia», 1999 & 4 & 2 & $12,5 \%$ \\
\hline
\end{tabular}

Tabla 2. Series de animación más vistas por los niños/as de Educación Infantil participantes en los sondeos. 
Una de las conclusiones más evidentes que se extraen a la luz de los resultados obtenidos durante estos primeros sondeos es que los niños/as de Educación Infantil son consumidores habituales de series con un alto contenido violento, un hecho del que ya se habían hecho eco con anterioridad numerosos investigadores (Aguaded, 1999; Domínguez y Frutos, 2002; García Galera, 2000; Pérez i Garcias y Urbina, 2005; Peters y Blumberg, 2002; Urra, Clemente y Vidal, 2000; etc.). Es en este momento cuando este estudio decide profundizar en el análisis del grado de comprensión que los niños/as tienen de estos mensajes agresivos. El propósito es llegar al conocimiento de cuál es el tipo de enseñanzas que adquieren a través de estos productos audiovisuales y de cuáles son los significados o conductas culturales que interiorizan siendo receptores de este tipo de señales. Para ello la investigación se adentra en lo que se ha denominado "primera etapa analítica".

\section{Primera etapa analítica: Elaboración de un registro que contextualiza temporalmente los símbolos culturales de las series audiovisuales violentas más populares de las últimas décadas}

Una vez que se decide focalizar la investigación en las series de animación de contenido violento se toma también la decisión de aplicar el método semiótico cultural en el análisis de las mismas. Para ello esta investigación se basa en los estudios de semiótica que han analizado las imágenes desde una perspectiva cultural, como ha hecho, por ejemplo, la investigadora Deborah Smith-Shank (2004), señalando que los estudios de semiótica cultural tratan los símbolos culturales que aparecen en las imágenes. Sin embargo, no es ella la única en sostener que las imágenes constituyen un lenguaje cultural analizable desde el punto de vista semiológico, y es que ya en el año 1997, Göran Sonesson, en su artículo "Semiótica cultural de la sociedad de imágenes. De la reproducción mecánica a la producción digital», publicado en la revista «Heterogénesis» sostenía que la sociedad de la información no es otra cosa que una sociedad de imágenes, afirmando que hoy en día se puede llegar a decir de la imagen lo mismo que en su día señalaron los formalistas rusos y la escuela de Praga de la palabra, esto es, que su función más importante es la puramente comunicativa.

Pero lo cierto es que el análisis de la imagen desde una perspectiva semióticocultural resulta particularmente complejo, pues los significados culturales cambian con el tiempo de forma inevitable, en función de los contextos y la propia 
comprensión humana. En base a esto, nunca es posible saber todo lo que un signo específico significa para otra persona, pues ésta lo abordará en función de sus propias experiencias, intereses y hábitos. Podría decirse, por lo tanto, que ningún autor ni receptor de imágenes posee la interpretación absoluta de un signo. A pesar de todo, autores como Bal y Bryson (199I) o Gillian Rose (200I) señalan que, en un proceso de comunicación basado en imágenes -como en el caso de las series de animación infantil con contenido violento que nos ocupa-, una vez que los signos visuales han sido identificados, es posible explorar sus significados a través del tiempo.

En base a estas teorías, esta investigación utiliza los recursos semiológicos como instrumentos de análisis con el fin de interpretar los diferentes significados culturales que se otorga al fenómeno de la violencia en las series de animación infantil de las últimas décadas. Se procede, entonces, a estudiar los significados culturales de la violencia y los personajes violentos que aparecen en las series de animación de los últimos treinta años.

La contextualización histórica elaborada en este estudio parte de los años 80 , una década que marca la aparición de un nuevo tipo de series en España: el animé japonés -que no es otra cosa que la adaptación de las novelas gráficas manga al audiovisual-. El gran éxito de estos productos entre el público estadounidense y europeo hace que su emisión vaya, desde entonces, aumentado de forma progresiva. Asimismo, su consumo, lejos de limitarse a la audiencia adulta, se extiende a gran escala entre el público infantil, que se hace permeable a su gran contenido violento.

Como primer ejemplo de violencia y popularidad se puede hablar de «Mazinger Z», emitida a partir de 1978. El argumento de esta serie se desarrolla en base a una guerra entre androides en la que la evolución de los artefactos robóticos es lo que determina el poder de ambos bandos. Este hecho hace que a lo largo de la trama las armas bélicas sean cada vez más innovadoras y, consecuentemente, mortíferas. Pero a pesar de su violencia, esta serie fue sólo la primera en emitirse con este tipo argumento de carácter belicista, y es que durante los años 80 nacen muchas más animaciones con temáticas similares y protagonizadas también por personajes robóticos. Por nombrar solo algunos ejemplos se puede hablar de «Transformers», estrenada en el año 84, o «Robotech», del 85. Esta obsesión por la robótica en las creaciones de ficción venía dada, muy probablemente, por la revolución tecnológica que el mundo vivía en aquellos momentos. Otras series 
de animé estrenadas también en los años 80 fueron "Los halcones galácticos» - "Los caballeros del zodiaco», ambas protagonizadas por grupos de jóvenes guerreros.

Pero sin duda, el gran animé de la época a nivel internacional fue «Dragon Ball» (1986), una serie que, si bien compartía una temática similar con las descritas anteriormente, superó con mucho el éxito de sus predecesoras. En este relato -bajo cuya superficie argumental se encuentran elementos procedentes de la mitología japonesa- el objetivo de sus protagonistas es el de llegar a un dominio total tanto de la tierra como del resto de universo. La trama comienza con una búsqueda iniciada por su personaje protagonista, Son Goku, que trata de reunir las denominadas «bolas de dragón», desafiando en su búsqueda a todo tipo de villanos para convertirse en el hombre más fuerte del mundo (lbarra y Robles, 2005). Además, en varios momentos la serie se centra en lo que ellos llaman el «tenkaichi budokai», un gran torneo mundial de artes marciales en el que los mejores luchadores de todo el mundo se dan cita, batiéndose en duelo con el fin de demostrar quién es el luchador más fuerte sobre la tierra. Sólo de forma posterior el argumento da un giro radical, haciendo que la búsqueda de las bolas de dragón pase a un segundo plano para centrarse en temáticas como la protección de la tierra y el universo. En esta serie la violencia, la representación de la mujer, el humor picante, irreverente $y$ absurdo $y$ otros contenidos no apropiados para menores, llegaron a provocar la prohibición de su emisión. Sin embargo, años más tarde se reincorporó de nuevo a la parrilla televisiva en horario infantil.

En definitiva, podría decirse que durante los años 80 las tramas de las series dirigidas al público infantil estaban dominadas por personajes heróicos dedicados a luchar por la humanidad. Un tipo de tramas que, lejos de limitarse al animé, se nutrían también de algunos de los personajes creados por la más popular editorial estadounidense de comics, la Marvel. Hablamos de casos como «Batman» (1992), «X-Men» (1992), "Spiderman (1994), «Los 4 Fantásticos» (1995), "Superman» (1996), «El Increíble Hulk» (1996), etc. Al igual que pasó con «Dragon Ball», muchas de estas series fueron censuradas tras sus primeras emisiones, pero durante los años 90 se empezaron a programar de nuevo.

Por otro lado, y en paralelo a las series hasta ahora descritas, durante las décadas de los 80 y 90 , e incluso a principios del siglo $X X I$, se crean también otros productos como «Los Simpson» (1987), «Doraemon» (1993), «Bob Esponja» 
(1999) ० "Shin Chan» (2005), en los que los rasgos de carácter violento tienen otros matices. No se trata, como en el caso anterior, de series que muestren de forma explícita contenidos bélicos o enfrentamientos violentos, sin embargo, sí que se pueden apreciar en ellas actitudes y acciones de tipo agresivo e incluso violencia de tipo verbal y psicológica como burlas o ridiculizaciones dirigidas hacia algún personaje. Por poner algunos ejemplos es posible hablar de los constantes cambios de humor de la figura materna en "Shin Chan", la agresividad de Homer Simpson con su hijo Bart, al que casi llega a estrangular en numerosas ocasiones - la inocencia del personaje de Novita en la serie Doraemon, un niño débil que se enfrenta constantemente a la violencia que contra él ejercen los niños más fuertes y corpulentos del colegio. En definitiva, si hay que caracterizar de alguna forma la violencia presente en las series de animación de los últimos años, puede definirse por su relación con el mundo real. Se trata de una violencia que se podría encontrar de forma cotidiana en algunos comportamientos sociales, aunque también es necesario decir que se refleja de forma cómica y grotesca, por su intención de inducir al espectador a la risa fácil.

Finalmente, a finales de los noventa se vuelven a emitir nuevas series de animé con grandes dosis de violencia. Este es el caso de «Pokemon» (1997) y «Digimon» (1999), dos series que basan su argumento en las luchas que tienen lugar entre unos monstruitos o criaturas fantásticas diferentes entre sí. Pero la más moderna de este tipo de series es «Los Gormiti», del año 2009. Este producto de animación ha cosechado hasta el momento un gran éxito entre los más pequeños y su trama se basa en la historia de cuatro niños que se transforman en "señores de la naturaleza» para luchar contra el mal y salvar la isla de Gorm.

En definitiva, puede decirse que, tras realizar este repaso de algunas de las series infantiles con contenidos violentos y de mayor repercusión de los últimos años, se ha observado, básicamente, la presencia de dos tipos de violencia:

- La que a partir de ahora llamaremos "violencia fantástica": Manifestada a través de los avances tecnológicos en el ámbito armamentístico y en la ambición por los villanos de conquistar el mundo o incluso la galaxia.

- La que denominaremos "violencia real caricaturizada": Una agresividad cotidiana, alejada de la lucha por el poder y más cercana a las rutinas familiares y sociales, representada de forma cómica por su intencionalidad crítica y para provocar la risa en el espectador. Este tipo de agresividad también se manifiesta en forma de violencia verbal o psicológica. 
En lo que respecta a la caracterización de los personajes, se han encontrado, dentro de la violencia fantástica, dos tipos de héroes y de villanos:

- Por un lado, en las series de tipo animé, los héroes son personajes de complexión fuerte pero de rasgos suaves y personalidad simpática y agradable, que se ven obligados a usar la violencia en la lucha contra "el mal". Mientras tanto, los villanos están representados, en su mayoría, por monstruos y seres de otro planeta, malvados por naturaleza y que utilizan la violencia para conseguir sus ambiciosos y, casi siempre, crueles objetivos.

- Por otro lado, en el resto de las series que cuentan con violencia fantástica, el protagonista suele ser un superhéroe único, con una vestimenta diferenciadora y de complexión fuerte, pero de personalidad noble y heroica. Este personaje, además, suele esconder sus poderes en público mostrándose ante el resto de la gente como una persona corriente. Frente a él, se encuentra el villano, encarnado por personajes fracasados con traumas que los han convertido en lo que son. Normalmente inteligentes, pero eternos perdedores en un mundo en el que el mal nunca triunfa.

Como dato final se puede señalar que la fortaleza es un rasgo que queda remarcado en todos los personajes de las series que cuentan con violencia fantástica, independientemente de su bondad o maldad parece importante la posibilidad de imponerse a los demás a través de métodos agresivos.

Por lo que respecta a la violencia real caricaturizada, cabe señalar que la caracterización tan polarizada de los personajes se pierde, actuando éstos como héroes o villanos en función de la situación.

Para terminar, y como resultado del análisis de las series de televisión nombradas hasta el momento, se ha elaborado, en el contexto de esta investigación, una cartografía (Tabla 3) en la que figuran algunos de los más importantes significados culturalmente otorgados al concepto de violencia y a los personajes violentos en las series de animación pertenecientes a la cultura visual infantil. 


\begin{tabular}{|c|c|c|c|}
\hline \multirow{2}{*}{$\begin{array}{l}\text { Series de animación } \\
\text { por fecha de estreno }\end{array}$} & \multirow{2}{*}{$\begin{array}{l}\text { Tipos de } \\
\text { violencia }\end{array}$} & \multicolumn{2}{|c|}{ Caracterización de los personajes } \\
\hline & & Héroes & Villanos \\
\hline «Mazinguer Z», 1978 & \multirow{5}{*}{$\begin{array}{l}\text { Violencia } \\
\text { fantástica }\end{array}$} & \multirow{5}{*}{$\begin{array}{l}\text { Personajes de } \\
\text { complexión fuerte } \\
\text { pero de rasgos } \\
\text { suaves y personalidad } \\
\text { simpática y agradable }\end{array}$} & \multirow{5}{*}{$\begin{array}{l}\text { Personajes de } \\
\text { complexión y rasgos } \\
\text { fuertes, malos por } \\
\text { naturaleza, que en } \\
\text { ocasiones son incluso } \\
\text { monstruos o seres de } \\
\text { otro planeta }\end{array}$} \\
\hline «Transformers», 1984 & & & \\
\hline «Robotech», | 985 & & & \\
\hline $\begin{array}{l}\text { "Los halcones } \\
\text { galácticos», I } 986\end{array}$ & & & \\
\hline «Dragon Ball», 1986 & & & \\
\hline «Los Simpson», 1987 & $\begin{array}{l}\text { Violencia real } \\
\text { caricaturizada }\end{array}$ & \multicolumn{2}{|c|}{$\begin{array}{c}\text { Todos los personajes son, al mismo tiempo, } \\
\text { héroes y villanos. }\end{array}$} \\
\hline «Batman», 1992 & \multirow{2}{*}{$\begin{array}{l}\text { Violencia } \\
\text { fantástica }\end{array}$} & \multirow{2}{*}{ Superhéroes } & \multirow{2}{*}{$\begin{array}{l}\text { Personajes fracasados } \\
\text { con traumas que los han } \\
\text { convertido en lo que son }\end{array}$} \\
\hline «X-Men», 1992 & & & \\
\hline «Doraemon», 1993 & $\begin{array}{l}\text { Violencia real } \\
\text { caricaturizada }\end{array}$ & \multicolumn{2}{|c|}{$\begin{array}{c}\text { Todos los personajes son, al mismo tiempo, } \\
\text { héroes y villanos. }\end{array}$} \\
\hline «Spiderman», 1994 & \multirow{6}{*}{$\begin{array}{l}\text { Violencia } \\
\text { fantástica }\end{array}$} & \multirow{3}{*}{ Superhéroes } & \multirow{3}{*}{$\begin{array}{l}\text { Personajes fracasados } \\
\text { con traumas que } \\
\text { los han convertido } \\
\text { en lo que son }\end{array}$} \\
\hline «Los 4 fantásticos», 1995 & & & \\
\hline «Superman», 1996 & & & \\
\hline «El increíble Hulk», 1996 & & \multirow{3}{*}{$\begin{array}{l}\text { Personajes de } \\
\text { complexión fuerte } \\
\text { pero de rasgos } \\
\text { suaves y personalidad } \\
\text { simpática y agradable }\end{array}$} & \multirow{3}{*}{$\begin{array}{l}\text { Personajes de complexión } \\
\text { y rasgos fuertes, malos } \\
\text { por naturaleza, que en } \\
\text { ocasiones son incluso } \\
\text { monstruos o seres de } \\
\text { otro planeta }\end{array}$} \\
\hline «Pokemon», 1997 & & & \\
\hline «Digimon», 1999 & & & \\
\hline «Bob Esponja», 1999 & \multirow{2}{*}{$\begin{array}{l}\text { Violencia real } \\
\text { caricaturizada }\end{array}$} & \multirow{2}{*}{\multicolumn{2}{|c|}{$\begin{array}{l}\text { Todos los personajes son, al mismo tiempo, } \\
\text { héroes y villanos. }\end{array}$}} \\
\hline «Shin Chan», 2005 & & & \\
\hline «Los Gormiti», 2009 & $\begin{array}{l}\text { Violencia } \\
\text { fantástica }\end{array}$ & $\begin{array}{l}\text { Personajes de } \\
\text { complexión fuerte } \\
\text { pero de rasgos } \\
\text { suaves y personalidad } \\
\text { simpática y agradable }\end{array}$ & $\begin{array}{l}\text { Personajes de } \\
\text { complexión y rasgos } \\
\text { fuertes, monstruos y } \\
\text { seres de otro planeta }\end{array}$ \\
\hline
\end{tabular}

Tabla 3. Contextualización de los significados dados al concepto de violencia y a los personajes violentos en las series de animación. 


\section{Segunda etapa empírica: El uso del dibujo infantil como herramienta de indagación sobre el significado cultural que dan los niños/as de Educación Infantil a las series de animación violentas a las que están expuestos/as}

Una vez elaborada la contextualización de los significados culturales dados al concepto de violencia en las series de animación infantil de las últimas décadas esta investigación se adentra en su última fase, denominada "segunda etapa empírica". En este momento el estudio da un paso más utilizando el dibujo infantil como herramienta de indagación (Cooke, 1886; Lowenfeld, 1958; Ricci, I887; Rouma, 1991). Para ello, se regresa a los tres centros en los que se realizó el estudio piloto -La Escuela Infantil Pública de Jun y los Colegios Públicos Al-Zawiya de la Zubia y Luis Rosales-, y, con la misma muestra de alumnado -48 niños de Educación Infantil-se realiza una actividad en la que se les pide que dibujen alguna escena de las series de televisión que ven habitualmente. Se trata, en definitiva, de trascender el concepto tradicional de enseñanza del dibujo para utilizar éste como una herramienta de investigación que permita conocer al investigador, de primera mano, las impresiones que el niño/a tiene de su propio entorno y de los referentes culturales audiovisuales a los que está expuesto. Con ello se pretende, tanto conocer qué significados o conductas culturales asimilan los niños/as a través de las series de televisión, como comprobar si alguno de estos significados son los mismos o equiparables a los observados en la contextualización de las series violentas realizada de forma previa por los investigadores. Asimismo, la práctica del dibujo infantil se complementa con la realización de entrevistas desestructuradas que tienen por objetivo inducir a los niños/as a que sean ellos mismos quienes den una interpretación a las imágenes que ejecutadas. El resultado es la recopilación de un total de 48 dibujos con sus respectivas entrevistas de contraste'.

A continuación recogemos algunos de los resultados más interesantes: 


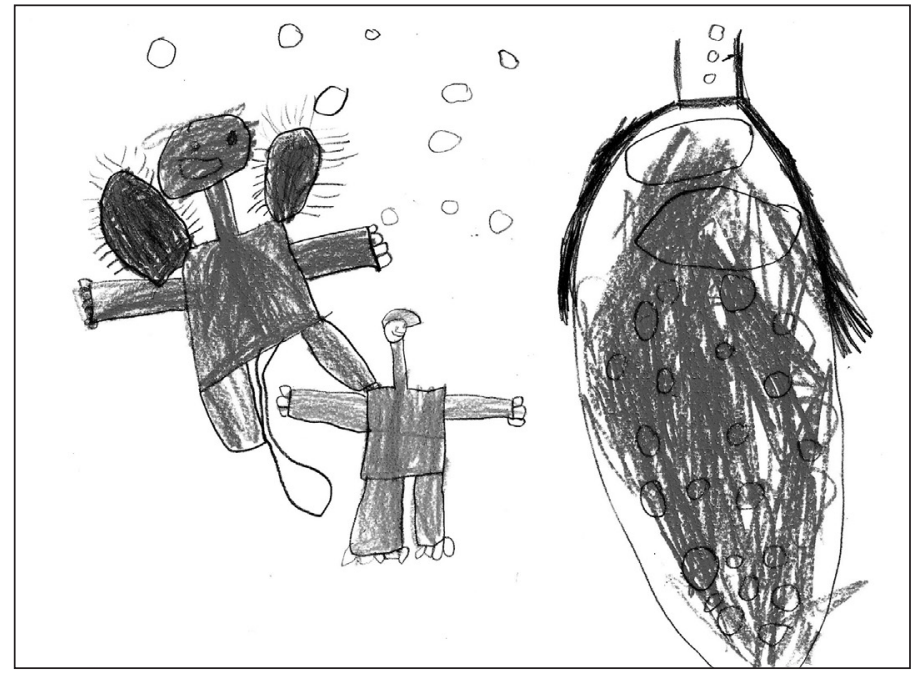

Figura I. Alejandro, 5 años. 210 x 297 mm. Ceras y lápiz sobre papel.

Alejandro representa, en la parte superior izquierda del papel y a mayor tamaño a un personaje de la serie de animación «Los Gormiti», a la cual hace referencia durante su entrevista. Este personaje se caracteriza por sus enormes hombreras recubiertas de púas, un detalle de carácter agresivo que el niño toma de la serie. Asimismo, a la derecha del dibujo el niño representa el lugar en el que se desarrolla la acción, un volcán en erupción del que está saliendo lava sobre el cual habla durante en la entrevista.

Transcripción fónica literal de un fragmento de la conversación mantenida con Alejandro durante la realización de su dibujo:

- Investigador: ¿Cuáles son las series de animación que más te gustan?

- Alejandro: Pues me gusta Bola de Dragón, los Gormiti.

- Investigador: ¿Y cómo son los personajes que aparecen?

- Alejandro: Pues son muy feos y son monstruos que luchan.

- Investigador: ¿Y cómo son los Gormiti?

- Alejandro: Pues... matan a los malos.

- Investigador: ¿Y me puedes decir cómo son los personajes malvados?

- Alejandro: Tienen que conseguir romper el volcán que salga toda la lava y si la casa se cae en el volcán los malos ganan. 


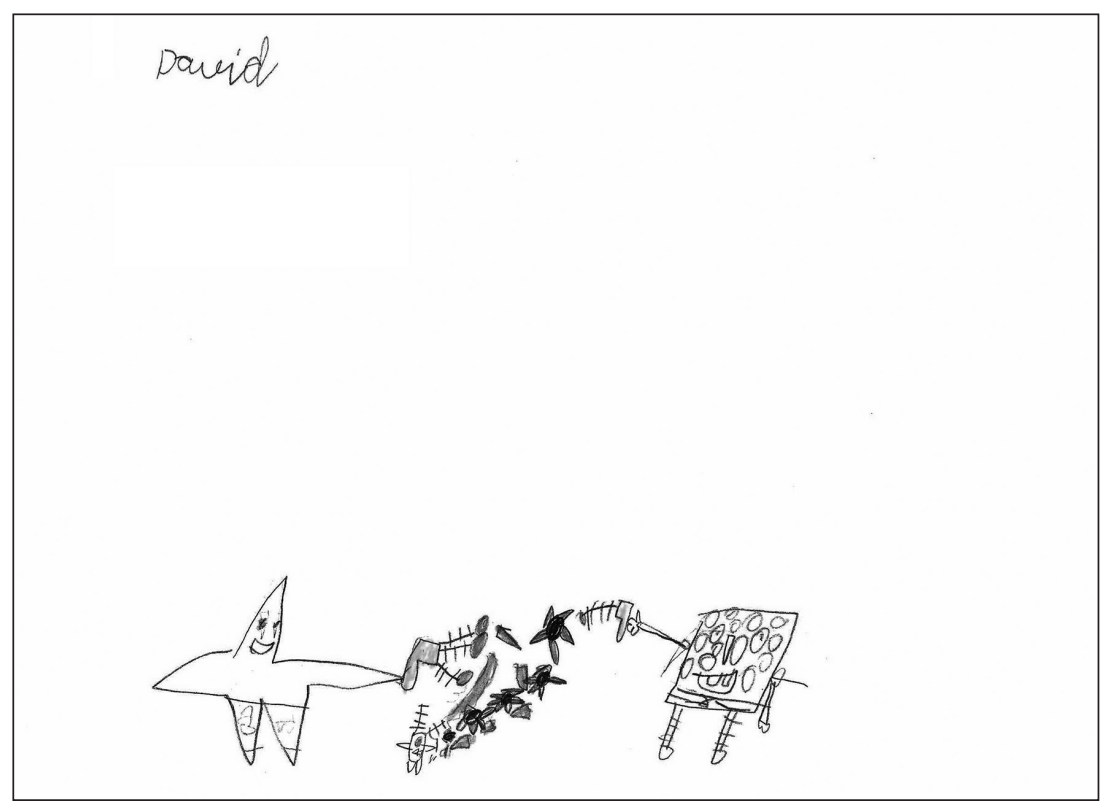

Figura 2. Iván, 6 años. 210 × 297 mm. Ceras y lápiz sobre papel.

Iván toma, claramente, un referente de la cultura visual actual, la serie de televisión «Bob Esponja» y se decanta por representar una escena de tipo violento poco característica para la serie en cuestión en la que los tres personajes principales "Bob Esponja, Patricio y Plankton" aparecen disparandose entre sí con armas de fuego. Aunque la representación de los personajes es muy fiel, lo cierto es que el niño se basa más en las escenas procedentes de series con violencia fantástica que en las escenas habituales de la serie «Bob Esponja», pues es muy poco común que en esta serie los personajes utilicen armas de fuego para enfrentarse los unos con los otros.

Transcripción fónica literal de un fragmento de la conversación mantenida con Iván durante la realización de su dibujo:

- Investigador: ¿Qué has dibujado aquí?

- Iván: Pues es que Bob Esponja tenía un arma y su arma lanzaba bolas de acero con fuego de pinchos y Patricio tenía un arma que tenía tres pistolas y lanzaba chorros de agua, agua y aire y Plankton fue destruido. 


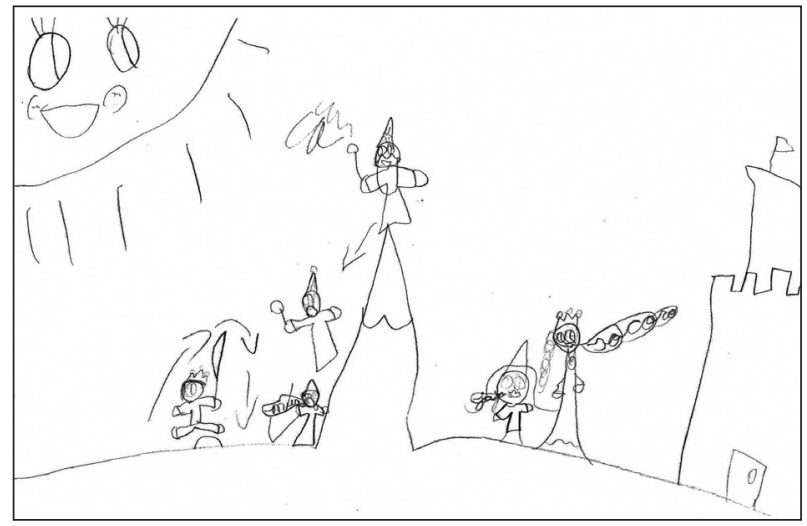

Figura 3. Estefanía, 6 años. $210 \times 297 \mathrm{~mm}$. Ceras y lápiz sobre papel.

En el caso de esta representación gráfica, realizada por Estefanía, no queda reflejada ninguna escena de carácter violento. Esta niña dibuja sólo cuatro personajes sobre el papel, que de izquierda a derecha son, según sus propias palabras: un príncipe, un mago, una bruja y una princesa. El mago está tres veces dibujado, pues la niña plasma una secuencia en la que éste se cae de lo alto de la montaña en la que se encuentra. Es posible ver cómo este movimiento aparece señalado con una flecha. La autora del dibujo no hace referencia a ninguna serie de animación e inventa sus propios personajes, en este caso relacionados con el mundo de las princesas, la magia y la fantasía.

Transcripción fónica literal de un fragmento de la conversación mantenida con Estefanía durante la realización de su dibujo:

- Investigador: Estefanía, ¿Me puedes decir que has dibujado?

- Estefanía: Pues esta era una bruja y este era un mago (señala la figura situada en la parte superior) y este mago estaba en la montaña haciendo un hechizo suyo y se cayó abajo, se estaba cayendo, cayendo, cayendo y se puso a llorar como pone aquí "muaaaaa" y este era un príncipe (señala la figura de la izquierda) y esta era una bruja (señala a los personajes de la derecha) que la princesa que gritaba "socorro, socorro" mientra la bruja se reía "jajajajaja".

- Investigador: Entonces ila bruja era mala?

- Estefanía: Sí, quería encerrar a la princesa en su propia torre.

- Investigador: ¿Y quién es este? (señalamos la figura de la izquierda).

- Estefanía: Ese es el príncipe que va a salvar a la princesa pero antes tenía que ocuparse del malo. 


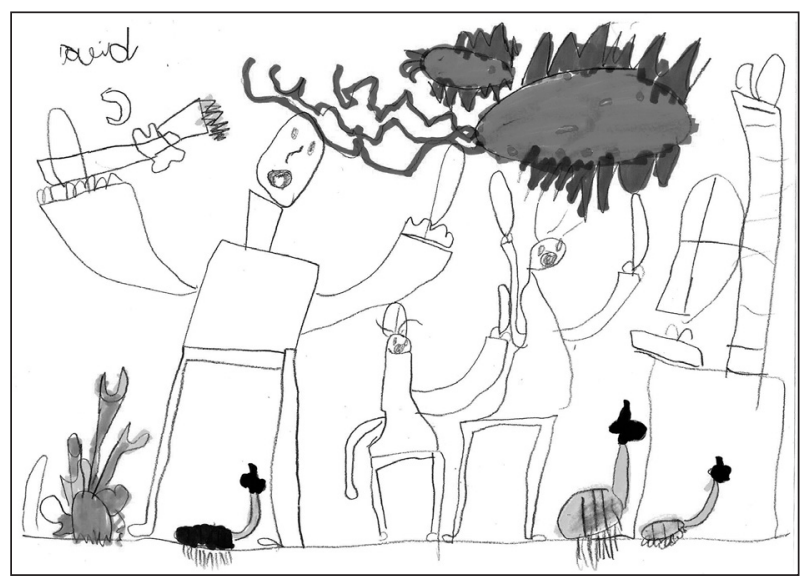

Figura 4. David, 5 años. $210 \times 297$ mm. Ceras y lápiz sobre papel.

Otro de los dibujos recogidos en este estudio es el realizado por David. Este niño hace una representación que reinterpreta libremente a los miembros de la familia Simpson, inventándose prácticamente toda la escena e introduciendo personajes de todo tipo. Además, dota a la imagen de una violencia poco característica de esta serie de televisión.

Transcripción fónica literal de un fragmento de la conversación mantenida con David durante la realización de su dibujo:

- Investigador: Cuéntame iqué has dibujado aquí?

- David: Este es Homer (señala el personaje de la izquierda).

- Investigador: ¿Y qué está haciendo?

- David: Está luchando con los malos.

- Investigador: ¿Y Homer lucha con los malos?

- David: Sí.

- Investigador: Y ¿qué más has dibujado?. A ver ¿quién es este que está aquí? (señalamos el personaje de la derecha).

- David: Bart Simpson.

- Investigador: ¿Y qué hace?

- David: Está peleando, ayuda a su padre a luchar con los malos.

- Investigador: ¿Y estás cosas de aquí?, ¿qué es esto de color naranja y amarillo?

- David: Esto son escorpiones y esto una "cucaracha" rarísima que quería entrar en su cueva. 
- Investigador: ¿Y estas cosas de aquí arriba qué son?

- David: Pues... son... una especie de extraterrestres que vienen de Marte y vienen a la tierra.

- Investigador: ¿Y has dibujado a la mamá de los Simpson?

- David: Pff... no...

- Investigador: ¿Y por qué no la has dibujado?

- David: Es que estaba en la cocina.

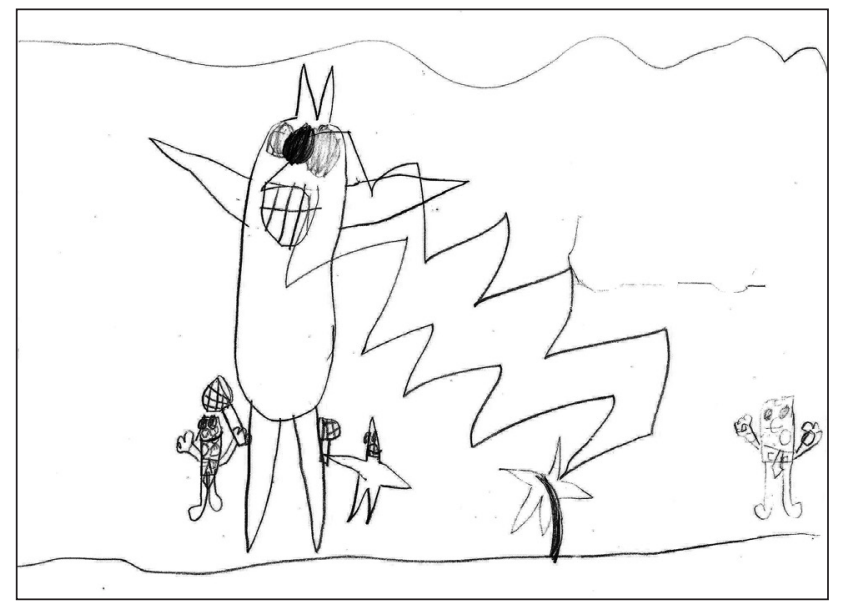

Figura 5. Marco, 5 años. 210 × 297 mm. Ceras y lápiz sobre papel.

Por último, Marco es, al igual que Iván, otro de los niños que hace un dibujo basado en la serie de animación «Bob Esponja». En este caso el niño realiza un claro retrato de Plankton, el villano de la serie, del que hemos hablado con anterioridad y que estaba ya presente en el dibujo de Iván. Aunque en su representación también aparecen Patricio y Bob Esponja estos tienen un tamaño mucho menor de lo que se deduce que el niño da más importancia a la figura del villano. Finalmente, cabe destacar que también este niño basa su dibujo en la representación de una escena de tipo violento poco característica de la serie original.

Transcripción fónica literal de un fragmento de la conversación mantenida con Marco durante la realización de su dibujo:

- Investigador: ¿Qué has dibujado? 
- Marco: Este es Plankton gigante y este Patricio (señala figura de la derecha) y Bob Esponja (señala la figura de la izquierda) y que le están dando con caza medusas y Plankton ha quemado una casa.

- Investigador: ¿Y por qué le están dando con un caza medusas a Plankton?

- Marco: Porque es muy malo.

Para terminar, los resultados obtenidos del total de los dibujos quedan recogidos en la Tabla 4.

\begin{tabular}{llll}
\hline $\begin{array}{l}\text { Series representadas } \\
\text { por los niños/as en sus dibujos }\end{array}$ & Género & $\begin{array}{c}\text { Presencia de } \\
\text { violencia en } \\
\text { los dibujos }\end{array}$ \\
\hline \multirow{2}{*}{ Series NO violentas } & Masculino & 3 & 1 \\
\cline { 2 - 4 } & Femenino & 8 & 0 \\
\hline Serie de violencia real caricaturizada & Masculino & 9 & 4 \\
\cline { 2 - 4 } & Femenino & 11 & 2 \\
\hline \multirow{2}{*}{ Serie de violencia fantástica } & Masculino & 13 & 13 \\
\cline { 2 - 4 } & Femenino & 4 & 3 \\
\hline
\end{tabular}

Tabla 4. Temática de los dibujos recogidos en la segunda etapa empírica de la investigación.

\section{Conclusiones}

Lo primero que hay que señalar a la hora de presentar las conclusiones de este estudio es que, como se puede observar en la Tabla 4, se han tenido en cuenta tres variables a la hora de analizar los dibujos recogidos:

- El tipo de serie representada en el dibujo en función de su violencia, es decir: series no violentas, series de violencia real caricaturizada -como «Los Simpson», «Bob Esponja», etc.- y series de violencia fantástica -como las series manga o de superhéroes-.

- La presencia de violencia dentro de la escena representada por el niño/a.

- La variable de género. 
Con respecto a la segunda variable, es decir, la presencia de violencia en los dibujos recogidos, se encontraron un total de 23 dibujos con escenas de tipo agresivo, lo que se corresponde con un $47,91 \%$ del total. Esto quiere decir que casi la mitad de los niños/as participantes en la investigación representaron en sus dibujos escenas de carácter violento. Al hilo de esto, y teniendo en cuenta la variable de género, cabe destacar que sólo 5 de los dibujos con escenas violentas fueron dibujados por niñas, frente a los 18 realizados por los niños. Si este dato es traducido a porcentaje, el resultado es que sólo un $21,73 \%$ de las niñas participantes han dibujado escenas de tipo violento, frente a un $72 \%$ de los niños.

Por otro lado, y con respecto a la primera variable señalada -que hace referencia al tipo de series elegidas por los niños/as para representar en sus dibujos- los resultados obtenidos reflejan que sólo un $22,91 \%$ de los niños/as (I I niños/as) han seleccionado series de tipo no violento para realizar su representación, mientras el $77,08 \%$ restante ( 37 niños/as) se ha decantado por series de animación con algún tipo de contenido violento. Concretamente, 17 niños/as han basado sus dibujos en series con presencia de violencia fantástica, frente a los 20 niños/as que lo han hecho en series con violencia real caricaturizada. La paradoja en este punto $-y$ lo que resulta, posiblemente, una de las aportaciones más interesantes de este estudio- es que se ha podido observar como, de estos 20 niños/as que han plasmado en sus representaciones series como "Los Simpson», "Bob Esponja», etc., sólo 6 han representado escenas de carácter agresivo, mientras los otros 14 han realizado interpretaciones personales de los contenidos de la serie dibujando momentos de carácter familiar, amistoso, mágico, etc. Además, de los 6 niños/as que han representado escenas de carácter agresivo, ninguno de ellos ha reflejado el tipo de violencia propia de esa clase de serie, caracterizada por su relación con el mundo real al ser un tipo de agresividad que, aunque exagerada, se puede llegar a encontrar de forma cotidiana en algunos comportamientos sociales. Más bien al contrario, estos dibujos representaban escenas similares a las que aparecen en los productos mangas y de superhéroes, con una violencia que aquí se ha denominado fantástica -armas, peleas, agresiones físicas, etc.-. Éste era el caso de alguno de los dibujos analizados en el apartado anterior, como los realizados por Iván, Marco o David. Por último, ningún niño/a ha realizado un dibujo en el que hubiese presencia de agresiones de tipo verbal o psicológico, por lo que podría decirse que los niños/ as no asimilan la violencia real caricaturizada. Esto puede deberse al hecho de que la asocian más a escenas de carácter cómico y grotesco que a escenas de tipo violento. 
En tercer lugar, y profundizando algo más en lo referente a la variable de género, también ha resultado de alto interés encontrar, sobretodo entre las niñas, la presencia de imaginarios culturales muy arraigados propios de los cuentos infantiles. Uno de estos casos es el de Estefanía, cuyo dibujo se analizaba también en el apartado anterior.

A modo de conclusión final, y en base a los datos obtenidos en este estudio, podría decirse que los niños/as de entre 5 y 6 años asimilan y reproducen algunos de los tipos de violencia que ven en los medios de televisión. Este es el caso de la que se ha denominado "violencia fantástica" que, si bien puede estar más circunscrita a un universo de ficción que la aquí llamada "violencia real caricaturizada" no deja de tener un componente más físico y material que podría llegar a afectar negativamente al comportamiento de los niños/as más pequeños, haciendo que reproduzcan de algún modo las conductas que observan en los medios de comunicación. Sin embargo, y también en base a los resultados aquí reflejados, hay que señalar que parece que los niños/as de Educación Infantil no son tan permeables a la violencia verbal o psicológica presente en las series de animación.

\section{Referencias bibliográficas}

Aguaded, J. (1999). Convivir con la television: familia, educación y recepción televisiva. Barcelona: Paidós.

Bal, M. y Bryson, N. (199I). Semiotics and art history. Art Bulletin, 73, (2), I74-208.

Buckingham, D. (2005). Educación en medios. Alfabetización, aprendizaje y cultura contemporánea. Barcelona: Paidós.

Cooke, E. (I885-1886). Art teaching and child nature. London Journal of Education, I885, 465, I, 886, 12 .

Domínguez, J. y Frutos, M. (2002). Violencia en dibujos animados. Documentos de trabajo social: Revista de trabajo y acción social, 27, I23-I43.

García Galera, C. (2000). Televisión, Violencia e Infancia. Barcelona: Gedisa.

Giroux, H. (1997). ¿Son las películas de Disney buenas para sus hijos?. En R. Steinberg y J. Kincheloe, Cultura Infantil y multinacionales (pp. 65-78). Madrid: Morata.

Ibarra, A. y Robles, Y. (2005). Dragon Ball Zy Los Simpson: Propuestas axiológicas en la televisión para la conformación de la vida política de la comunidad infantil. Comunicación y sociedad, 3, 67-94. 
Leiva, E. y González, J. (2000). Análisis de El Rey León, La Disneylandización social. Comunicar, I4, I47-I52.

Lipsky, D. y Abrams, A. (1994). Late bloomers. Nueva York: Time Books.

Lowenfeld, V. (1958). El niño y su arte. Buenos Aires: Kapelusz.

Pérez i Garcias, A. y Urbina, S. (2005). Violencia en los dibujos de ayer y hoy. Comunicar, 25. Ejemplar dedicado a: Televisión de calidad: Congreso Hispanoluso de Comunicación y Educación. Huelva. [CD-ROM].

Peters, K. y Blumberg, F. (2002). Cartoon violence: Is it as detrimental to preschoolers as we think? Early Childhood Education Journal, 29, 3, I43-I48.

Ricci, C. (I886). L'arte dei bambini. Bolonia: N. Zanichelli.

Rose, G. (200I). Visual methodologies. London: Sage.

Rouma. G. (1919). El lenguaje gráfico del niño. Psicología del dibujo espontáneo de los niños. La Habana: La Propagandista.

Smith-Shank, D. (2004). What's your sing? Searching for the semiotic self. En D. Smith-Shank, (Ed.), Semiotics and Visual Culture: Sights, Signs, and Significance (pp. I -4). Virginia: National Art Education Association.

Sonesson, G. (1997). Semiótica de la cultura de la sociedad de imágenes. De la reproducción mecánica a la producción digital. Heterogénesis, 20, 16-37.

Steinberg, R. y Kincheloe, J. (2000). Cultura infantil y multinacionales. Madrid: Morata.

Urra, J., Clemente, M. y Vidal, M. (2000). Televisión: Impacto en la infancia. Madrid: Siglo XXI.

\section{Notas}

I. Es necesario señalar en este punto que no es posible relacionar cada uno de los dibujos recogidos con las series vistas por cada niño/a. Esto es así porque los datos acerca de las series más consumidas a través del medio televisivo por los niños/as de Educación Infantil -datos obtenidos durante el estudio piloto-, se analizaron de forma ciega, teniendo en cuenta la muestra en su conjunto y no la particularidad de cada uno de los casos. 